- Review Article

\title{
Fruit Intake to Prevent and Control Hypertension and Diabetes
}

\author{
Hyun Ah Park* \\ Department of Family Medicine, Inje University Seoul Paik Hospital, Inje University College of Medicine, Seoul, Korea
}

Fruits are considered healthy because of their high antioxidant, vitamin, mineral, fiber, and phytochemical contents. However, their high sugar content is a concern for glucose, lipid, and uric acid metabolism. We reviewed related articles published in the last 10 years and summarized evidence that relates fruit intake to the prevention and control of hypertension and diabetes mellitus. Clinicians should familiarize themselves with appropriate fruit intake to counsel at-risk patients on hypertension and diabetes.

Keywords: Fruit; Blood Pressure; Blood Glucose; Hypertension; Diabetes Mellitus

Received: September 11, 2020, Revised: October 4, 2020, Accepted: October 11, 2020

*Corresponding Author: Hyun Ah Park https://orcid.org/0000-0003-2343-8964

Tel: +82-2-2270-0097, Fax: +82-2-2270-0902, E-mail: drparkhyunah@gmail.com 


\section{INTRODUCTION}

Approximately $80 \%-90 \%$ of fruit mass is composed of water. Along with vegetables, fruits are a fiber-rich food; fruit flesh has large amounts of soluble fiber, while fruit skin has large amounts of insoluble fiber. Fruits contain vitamins B, C, and E, beta-carotene, folate, and minerals such as Mg and K. Fruits rarely contain fat, saturated fatty acids, cholesterol, and sodium. ${ }^{1,2)}$

Fruits are considered healthy and are known for having low energy density while being highly satiating due to their fiber and water content. Nutrients such as vitamins $\mathrm{C}$ and $\mathrm{E}$, beta-carotene, and phytochemicals exert antioxidant effects. In most cases, fruits are consumed raw as a dessert or a snack, and therefore, have the potential to replace energy-dense snacks. ${ }^{2)}$

A combination of fruits and vegetables is recommended for a healthy diet. Nutrients and phytochemicals in fruits and vegetables have been postulated to lower blood pressure by improving endothelial function, modulating baroreflex sensitivity, causing vasodilation, and increasing anti-inflammatory activity. ${ }^{3,4)}$ However, unlike vegetables, fruits contain high levels of sugars, including fructose, glucose, and saccharose (Table 1). ${ }^{5)}$ Furthermore, the sugar content in fruits may cause a high postprandial insulin level that predisposes individuals to diabetes and may increase uric acid production, which is associated with both elevated blood pressure and insulin resistance. ${ }^{6,7)}$ Fruit intake without substitution of other foods leads to increased energy intake and weight gain, which in turn leads to higher blood pressure and blood glucose levels. Furthermore, processed fruit juices have nutrient profiles that are slightly different to those of raw fruits, including higher

Table 1. Energy and sugar contents of fruits and fruit juice (per $100 \mathrm{~g}$ )

\begin{tabular}{lcc}
\hline Fruits and fruit juice & Energy (kcal) & Sugar $(\mathrm{g})$ \\
\hline Apple, Fuji & 56 & 11.1 \\
Apple juice & 42 & 10.0 \\
Banana & 84 & 14.6 \\
Blueberry & 43 & 5.8 \\
Grape & 57 & 11.9 \\
Grape juice & 47 & 10.9 \\
Kiwi, green & 66 & 6.7 \\
Korean melon & 47 & 9.1 \\
Mango & 61 & 13.6 \\
Muskmelon & 40 & 8.3 \\
Nectarine & 32 & 4.7 \\
Orange & 47 & 9.2 \\
Orange juice & 34 & 6.5 \\
Peach & 49 & 9.5 \\
Pear, Oriental & 46 & 9.8 \\
Persimmon, ripe & 65 & 12.3 \\
Pineapple & 53 & 10.3 \\
Strawberry & 34 & 6.1 \\
Satsuma & 39 & 8.0 \\
Watermelon & 31 & 5.1 \\
\hline
\end{tabular}

From Ministry of Food and Drug Safety. Korea nutrient database for standard reference. Cheongju: Ministry of Food and Drug Safety; 2020. ${ }^{5)}$ sugar levels and lower dietary fiber and phytochemical levels.

The purpose of this study was to evaluate the relationship between fruit intake, separate from vegetable intake, and type 2 diabetes (T2D) or hypertension by examining previous studies on this subject, in order to suggest appropriate fruit intake for the prevention and control of T2D and hypertension.

\section{REVIEW METHODS}

We reviewed longitudinal and experimental studies and their metaanalyses, and meta-analysis of these studies, which assessed the relationship between fruit intake and hypertension or T2D in adult participants. The included studies were published in English peer-reviewed journals after 2010. We searched PubMed, Embase, and Google Scholar using the following terms: fruit AND diabetes, fruit AND blood glucose, fruit and hypertension, fruit and blood pressure. Additionally, manual searches were performed.

Studies were excluded if they were on specific fruit extracts (e.g., flavonoids) or powders, on a specific fruit that is not commonly consumed (e.g., dragon fruit), involving specific fruit biomarkers (e.g., carotenoids, vitamin $\mathrm{C}$ ), on the combined effect of fruit and vegetables, in which the effect from fruit could not be distinguished from that of vegetables, on pregnant women or participants with health concerns (e.g., chronic renal failure), and on any dietary patterns including fruits. As for controlled trials, we restricted our analysis to studies that attempted to promote or increase fruit intake without specifying other dietary changes to closely replicate the scenario of increasing fruit intake in freely living human populations.

\section{EPIDEMIOLOGY OF FRUIT INTAKE}

In 2018, the mean ( \pm standard error) fruit intake of Korean adults $>19$ years old was $129.2 \pm 5.2 \mathrm{~g}$ for males and $160.5 \pm 5.1 \mathrm{~g}$ for females, while the total mean fruit intake was $144.9 \pm 4.1 \mathrm{~g}$ for both sexes. Fruit intake increased with increasing age. In females, the maximum intake decreased in women in their $50 \mathrm{~s}(228.3 \pm 15.2 \mathrm{~g})$ and $60 \mathrm{~s}(188.7 \pm 11.8 \mathrm{~g})$ (Figure 1). ${ }^{8)}$

The mean sugar intake for Koreans aged $>19$ years was $62.9 \pm 1.2 \mathrm{~g} / \mathrm{d}$ for males and 53.0 $\pm 1.0 \mathrm{~g} / \mathrm{d}$ for females based on the 2018 Korea National Health and Nutrition Examination Survey. ${ }^{9)}$ Fruits were ranked 1st on the list of dietary sugar sources $(22.8 \%)$, followed by fruit beverages and drinks (20.0\%), and dairy products (12.9\%).

\section{RECOMMENDATIONS ON FRUIT INTAKE}

\section{Korea Nutrition Society}

The 2005 Korea Nutrition Society recommends that people consume 1-4 servings of fruit per day, supposing that a single serving is $50 \mathrm{kcal}$ (Figure 2). ${ }^{10)}$ The recommended fruit varies according to the total energy intake, and is balanced with the intake of other foods. For example, in adults consuming $1,000 \mathrm{kcal} / \mathrm{d}, 1$ serving of fruit ( $50 \mathrm{kcal}$ ) is rec- 

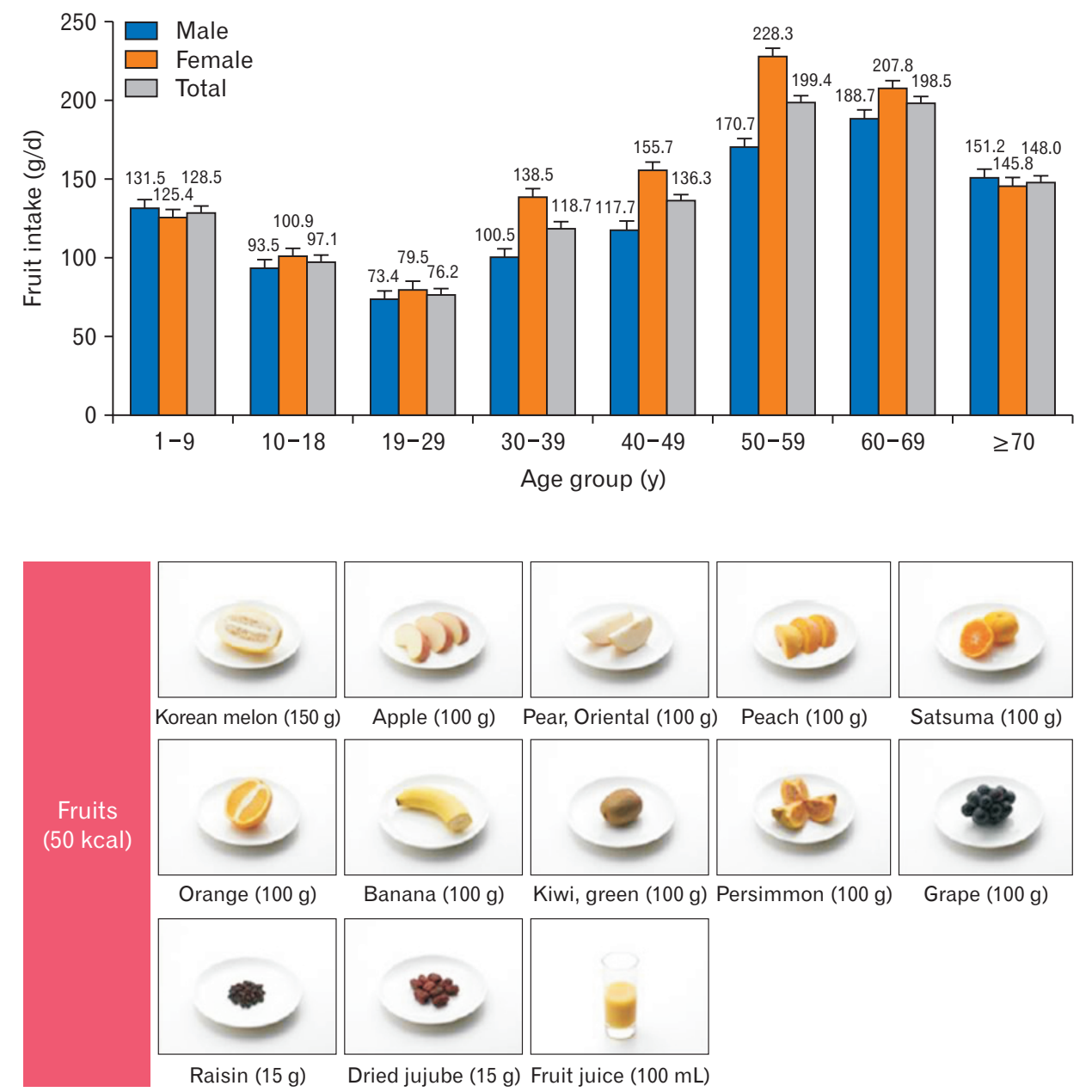

Korean melon (150 g)

Apple $(100 \mathrm{~g})$

Pear, Oriental (100 g)
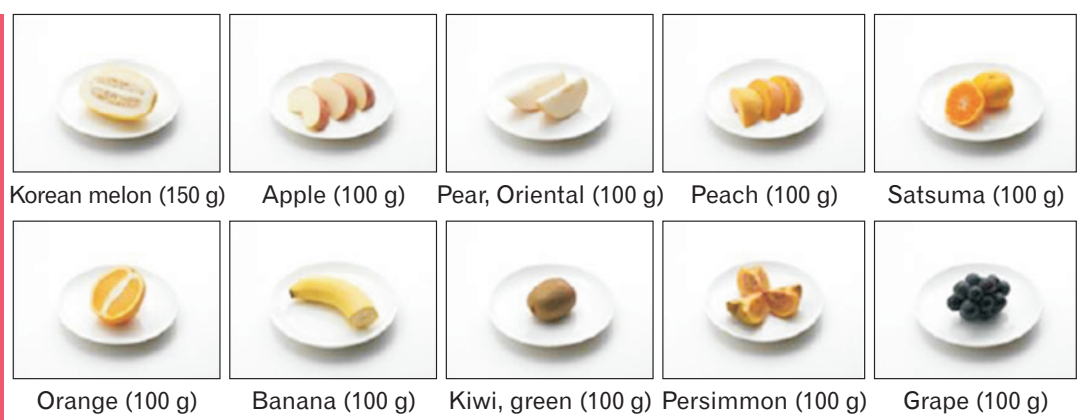

Banana $(100 \mathrm{~g})$

Kiwi, green $(100 \mathrm{~g})$ Persimmon $(100 \mathrm{~g})$

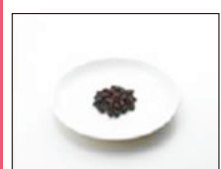

Raisin (15 g)

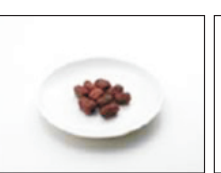

Dried jujube $(15 \mathrm{~g})$ Fruit juice $(100 \mathrm{~mL})$
Figure 2. One serving of fruit for Koreans from the Korea Nutrition Society. From Korea Nutrition Society. Dietary reference intakes for Koreans 2015. Seoul: Korea Nutrition Society; $2015 .^{10)}$ ommended, while for those consuming 2,800 kcal/d, 4 servings (200 $\mathrm{kcal}$ ) are recommended.

\section{U.S. Department of Agriculture}

The U.S. Department of Agriculture used the term "MyPlate" in a public nutrition guide to inform how much of each food group should be consumed. ${ }^{11)}$ "My plate" is a food circle that depicts a plate and glass, which recommends the consumption of approximately $10 \%$ fruit, $30 \%$ grains, $40 \%$ vegetables, and $20 \%$ protein, accompanied by a smaller circle representing dairy, such as a glass of milk or a cup of yogurt.

\section{World Health Organization}

The World Health Organization advises the intake of a minimum of $400 \mathrm{~g}$ of fruits and vegetables combined per day for the prevention of chronic diseases such as heart disease, cancer, diabetes, and obesity. ${ }^{12)}$

\section{Diabetes and Hypertension-Related Organizations}

The Korean Diabetes Association advises that carbohydrates should represent $50 \%-60 \%$ of the total energy intake. ${ }^{13)}$ In addition, they advise that consumed carbohydrates should consist of whole grains, fruits, vegetables, and low-fat dairy foods, although they do not recom-
Figure 1. Fruit consumption of Koreans by age group and sex. From Ministry of Health and Welfare. Korea health statistics 2018: Korea National Health and Nutrition Examination Survey (KNHANES VII-3). Sejong: Ministry of Health and Welfare; 2019. ${ }^{8)}$ mend a specific intake of fruit.

The Standards Medical Care of Diabetes 2020 of the American Diabetes Association recommends that carbohydrate intake should comprise nutrient-dense carbohydrate sources that are high in fiber and are minimally processed. ${ }^{14)}$ Fruits are recommended as a part of a healthy eating plan together with non-starchy vegetables, minimally added sugars, whole grains, and dairy products. The recommended fruit intake was not specified. People with diabetes and those at risk are advised to replace sugar-sweetened beverages (including fruit juices) with water as much as possible.

The Korean Society of Hypertension ${ }^{15)}$ and the 2017 American College of Cardiology/American Heart Association ${ }^{16)}$ advised the Dietary Approaches to Stop Hypertension dietary pattern, a diet rich in fruits, vegetables, whole grains, and low-fat dairy products, with reduced saturated and total fat, to lower blood pressure and normalize lipid metabolism. Again, the recommended fruit intake was not specified.

\section{TYPE 2 DIABETES}

\section{Does Fruit Increase the Risk of Type 2 Diabetes?}

Fruit intake seems to decrease the risk of T2D with varied effect sizes. 
In the meta-analysis by Li et al., ${ }^{17)}$ including 11 studies, a $106 \mathrm{~g} / \mathrm{d}$ increase in fruit intake was associated with a $6 \%$ lower risk of T2D (relative risk [RR], 0.94; 95\% confidence interval [CI], 0.89-1.00), while in the meta-analysis by Schwingshackl et al., ${ }^{18)}$ including 13 studies, each additional daily intake of $100 \mathrm{~g}$ of fruit was inversely associated with a $2 \%$ risk reduction (RR, 0.98; 95\% CI, 0.97-1.00).

However, the protective dose-response relationship between fruit intake and T2D was only significant up to a certain point. In four doseresponse meta-analyses, fruit intake and T2D incidences showed a curvilinear association, while the amount of fruit intake for the maximum protective effect was similar between studies. The study by $\mathrm{Li}$ et al. ${ }^{17)}$ showed that the nadir was 2 servings ( $212 \mathrm{~g}$ ) per day to 2.6 servings (276 g) per day, Schwingshackl et al. ${ }^{18)}$ reported a nadir of 200-300 g/d (with a $10 \%$ risk reduction), Li et al. ${ }^{19)}$ reported a nadir of $200 \mathrm{~g} / \mathrm{d}$ (with a $13 \%$ risk reduction), and $\mathrm{Wu}$ et al. ${ }^{20)}$ reported a nadir as 2 servings ( $212 \mathrm{~g}$ ) per day (with a $12 \%$ risk reduction). Intake beyond this point either showed no protective effect ${ }^{18-20)}$ or even an increase in T2D risk. ${ }^{17)}$

In summary, the recommended intake of fruit for the prevention of T2D appears to be approximately $200 \mathrm{~g} / \mathrm{d}$.

\section{Do Differences Exist between Types of Fruit?}

There is limited research on the association between individual fruits and hypertension. The combined analysis of health professional cohorts, including the Nurses' Health Study (NHS) I, II and the Health Professionals Follow-up Study (HPFS), showed that the risk of T2D differed significantly among individual fruits. ${ }^{21)}$ Greater consumption of blueberries ( $25 \%$ [95\% CI, 13\%-34\%] risk reduction for every 3 servings/wk, same for that which follows), grapes (12\% [7\%-17\%]), apples and pears (7\% [4\%-10\%]), bananas (5\% [2\%-9\%]), and grapefruits (5\% $[1 \%-9 \%])$ were significantly associated with a lower risk of T2D, while prunes, peaches and apricots, oranges, and strawberries showed no significant protective effect. Interestingly, the intake of 3 servings of cantaloupe per week increased the risk of T2D by $10 \%$ (RR, 1.10; 95\% CI, 1.02-1.18). The three cohorts showed similar associations. The authors suggested that the differential association of individual fruits may be partly due to the heterogeneous composition of phytochemicals such as anthocyanins or chlorogenic acid. They also suggested that the lower levels of phytochemicals in cantaloupes contributed to its detrimental effects.

The Singapore Chinese Health Study, with 484,742 person-years and a follow-up of 45,411 participants, reported the consumption of temperate fruit, such as apples, pear, apricots, grapes, peaches, and persimmons was associated with a lower risk of T2D in women only (hazard ratio [HR], 0.94; 95\% CI, 0.91-0.98 per 3 servings/wk). ${ }^{22)}$

In summary, while there is difficulty in reaching a conclusion due to the limited number of studies, temperate fruits such as apples, pears, and grapes appears to have a protective effect on T2D risk.

\section{How about the Consumption of Fruit Juice?}

A meta-analysis including 17 cohort studies showed that increased consumption of fruit juice (sweetened fruit juice+ $100 \%$ fruit juice) by 1 serving/d was associated with a 7\% greater incidence of T2D (95\% CI, $0.8 \%-14 \%){ }^{23)}$ Moreover, by replacing 3 servings/wk of fruit juice with the same amount of whole fruits, the risk of T2D was lowered by $7 \%$ $(4 \%-9 \%)^{21)}$

Furthermore, a meta-analysis including four studies on sugarsweetened fruit juice and four studies on $100 \%$ fruit juice reported that a higher intake of sugar-sweetened fruit juice was significantly associated with the risk of developing T2D ( $R R$ of the highest quartile versus the lower quartile intake, 1.28; 95\% CI, 1.04-1.59), but the intake of $100 \%$ pure fruit juice was not (RR, 1.03; 95\% CI, 0.91-1.18). ${ }^{24)}$ Unfortunately, as this study used quartile analysis, the healthy amount of $100 \%$ fruit juice intake could not be specified. However, we should note that the highest quartile group of each individual study consumed approximately one glass per day.

In summary, while a higher intake of sugar-sweetened fruit juice was significantly associated with the risk of T2D, the intake of $100 \%$ fruit juice was not. However, there is a possibility to reduce the risk of T2D by consuming raw fruits instead of their juices.

\section{Do Risks Differ by the Glycemic Index or Glycemic Load of Fruits?}

A higher total dietary glycemic load is associated with a greater risk of T2D. ${ }^{25)}$ However, the pooled analysis of three cohorts of NHS I, II, and HPFS with 3,464,641 person-years of follow-up showed that the differences in the glycemic index or glycemic load value of fruits did not account for the association between specific fruits and the risk of T2D. ${ }^{21)}$ This apparent discrepancy might be due to the fact that, compared to the whole dietary glycemic load, the contribution of total fruit consumption is rather small, at about $10 \%{ }^{21)}$ Therefore, it can be assumed that $90 \%$ of other foods played a greater role.

In summary, as fruits comprise a small proportion of the glycemic load compared to the entire meal, the glycemic load of fruits does not affect the risk of T2D.

\section{Will Blood Glucose Levels Decrease If Patients with Diabetes Consume Less Fruit?}

A small 12-week randomized controlled trial (RCT) that included 63 overweight men and women with newly diagnosed T2D showed that being prescribed a diet with reduced fruit intake to no more than 2 pieces per day (low-fruit group), as part of standard medical nutrition therapy, resulted in patients eating less fruits $(52 \mathrm{~g} / \mathrm{d}$ ) than those who were prescribed at least 2 pieces of fruit per day (high-fruit group, 125 $\mathrm{g} / \mathrm{d}){ }^{26)}$ However, despite a significant difference in fruit intake, there was no significant difference in the decrease of hemoglobin Alc (HbAlc) level or body weight. The most likely explanation for this is that in a free-living population, changes in the amount of fruit intake may lead to other changes, such as an increase or decrease in the intake of other foods. As a result, the authors recommended that fruit intake should not be restricted in patients with T2D. Moreover, a 6-month RCT on 152 patients with T2D recommended either a lower glycemic index or high cereal fiber diet; the results demonstrated that 
an increase in low glycemic index fruits $(<70)$, including apples, pears, citrus fruit, berries, and prunes, significantly reduced the HbAlc level $(\mathrm{r}=-0.21, \mathrm{P}=0.011)$, but changes in total fruit intake did not. ${ }^{27)}$ The authors suggested that a small amount of fructose released from low glycemic index fruits might "prime" the glucose metabolism to reduce postprandial glucose levels and increase hepatic glycogen synthesis. $^{28,29)}$

In summary, recommendations to increase fresh fruit consumption had no significant negative impact on glycemic control in patients with T2D. Indeed, it is possible that increasing the intake of lower glycemic index fruits improves glycemic control in patients with diabetes.

\section{What Is the Impact of Fruit Intake of Patients with Type 2 Diabetes on Complications and Mortality?}

The Japan Diabetes Complications Study followed 978 patients with diabetes for 9 years and showed that the risk for diabetic retinopathy declined with increased intake of fruits. The HRs for the second (83 g/ d), third ( $141 \mathrm{~g} / \mathrm{d})$, and fourth quartiles $(253 \mathrm{~g} / \mathrm{d})$ of fruit intake compared with the first quartile ( $23 \mathrm{~g} / \mathrm{d}$ ) were 0.66 (95\% CI, 0.46-0.92), 0.59 (95\% CI, 0.41-0.85), and 0.48 (95\% CI, 0.32-0.71). ${ }^{30)}$ A 7-year follow-up study of 30,300 Chinese adults with diabetes showed that each daily portion ( $100 \mathrm{~g}$ ) of fruit was associated with a HR of 0.83 (95\% CI, 0.740.93 ) for all-cause mortality, 0.59 (95\% CI, 0.40-0.87) for diabetes mortality, 0.78 (95\% CI, 0.65-0.93) for cardiovascular disease mortality, 0.72 (95\% CI, 0.61-0.87) for microvascular complications, and 0.87 (95\% CI, 0.82-0.93) for macrovascular complications, up to 40 portions $(4,000 \mathrm{~g})$ per month. Neither of the studies could explain the exact protective mechanism of fresh fruit consumption on diabetic complications. However, the anti-oxidative, anti-inflammatory, anti-atherogenic, and glycemic control effects of fruits were suggested to be the cause. $^{31)}$

In summary, fresh fruit consumption up to $133 \mathrm{~g}$ per day decreased the risk of complications and mortality in patients with T2D.

\section{HYPERTENSION}

\section{Does Fruit Intake Prevent Hypertension?}

Three dose-response meta-analyses on the relationship between fruit intake and incident hypertension were found. The meta-analyses of Wu et al. ${ }^{32)}$ (including nine cohorts), Schwingshackl et al. ${ }^{33)}$ (including seven cohorts), and Liu et al. ${ }^{34)}$ (including 12 cohorts) showed a similar protective linear association between fruit intake and the risk of hypertension. ${ }^{34)}$ While Wu et al. ${ }^{32)}$ showed that an increase in a serving (106 g) per day of fruit decreased the risk of hypertension by $1.9 \%$ (RR, 0.981; 96\% CI, 0.973-0.989), Schwingshackl et al. ${ }^{33)}$ showed that fruit intake of $100 \mathrm{~g} / \mathrm{d}$ decreased the risk of hypertension by 3.0\% (RR, 0.97 ; 96\% CI, 0.96-0.99). Moreover, Liu et al. ${ }^{34)}$ showed that fruit intake of $240 \mathrm{~g}$ (3 servings/d) decreased the risk of hypertension by $6.0 \%$ (RR, 0.94; 96\% CI, 0.93-0.96). The meta-analyses of Wu et al. ${ }^{32)}$ and Liu et $\mathrm{al}^{34)}$ showed an inverse linear dose-response relationship up to 5 servings/d (530 g/d and $640 \mathrm{~g} / \mathrm{d}$, respectively). The meta-analysis of
Schwingshackl et al. ${ }^{33)}$ showed a significant nonlinear dose-response trend, with the strongest risk reduction at 2 servings per day $(160 \mathrm{~g} / \mathrm{d})$, at which point the risk of hypertension decreased by $7 \%$. However, higher fruit consumption of 3 servings ( $240 \mathrm{~g}$ ) to 5 servings ( $400 \mathrm{~g}$ ) per day did not lower the hypertension risk further.

The Korean Genome and Epidemiology Study, a community-based study of Korean adults, also showed a similar inverse association between fruit intake and incident hypertension. ${ }^{35)}$ After 8 years of followup, frequent fruit consumers ( $\geq 4$ servings [ $400 \mathrm{~g}$ ] per day) had a $56 \%$ lower risk of incident hypertension than infrequent consumers among men ( $<1$ serving [100 g] per day) (HR, 0.44; 95\% CI, 0.32-0.60; P-for trend $<0.0001$ ) and a $67 \%$ lower risk among women (HR, 0.33; $0.24-$ 0.45 ; P-for trend $<0.0001$ ).

Interestingly, the baseline fruit intake was not the only intake that showed a protective effect on the risk of hypertension, but also the increased intake of fruits during the follow-up period. The combined analysis of three large health professional cohorts, the NHS I, II, and the HPFS, showed that patients whose fruit intake increased by $\geq 7$ servings/wk in the preceding 8 years were $6 \%$ (3\%-10\%) less likely to develop hypertension compared to participants who did not increase their fruit consumption. ${ }^{36)}$ The China Health and Nutrition Survey showed a similar protective effect, in that each standard deviation increase in fruit intake during the 5-year follow-up was associated with a 0.273 ( 0.058 to $0.487 ; \mathrm{P}=0.013) \mathrm{mm} \mathrm{Hg}$ decrease in diastolic blood pressure, and a $0.264(-0.578$ to $0.049 ; \mathrm{P}=0.098) \mathrm{mm} \mathrm{Hg}$ decrease in systolic blood pressure. ${ }^{37)}$

In summary, a fruit intake of up to $530-600 \mathrm{~g} / \mathrm{d}$ is protective against incident hypertension.

\section{Are There Differences between Fruit Species?}

There is limited research on the association between the types of fruits and hypertension. The combined analysis of three large health professional cohorts, the NHS I, II, and the HPFS with more than 20 years of follow-up, evaluated the relationship between fruit intake and hypertension. ${ }^{36)}$ The results showed that higher intakes of raisins/grapes $(\mathrm{P}<0.001)$, apples/pears $(\mathrm{P}<0.001)$, blueberries $(\mathrm{P}=0.01)$, and avocados $(\mathrm{P}<0.001)$ were associated with a decreased risk of hypertension. However, strawberries (P-for trend=0.79) showed no significant association, and cantaloupes showed an increased risk of hypertension $(\mathrm{P}=0.002)$. When consumed more than 4 times a week compared to less than once a month, cantaloupes increased the risk of hypertension by $7 \%$ (HR, 1.07; 95\% CI, 1.01-1.13) while apples and pears (frequently consumed in Korea), led to a $9 \%$ decrease in hypertension risk (HR, 0.91; 95\% CI, 0.88-0.95).

The Women's Health Study, including 28,082 women, evaluated the relationship between individual fruit species and the risk of hypertension over a period of 12.9 years. ${ }^{38)}$ The results demonstrated a reduced risk of hypertension with higher fruit intake, particularly for apples and oranges. Compared to women who consumed the respective food items rarely, the HR for hypertension was 0.91 (95\% CI, 0.84-0.99) for those consuming $>4$ servings of apples per day, and 0.91 (95\% CI, 
0.84-0.98) for those consuming $>4$ servings of oranges per day. Bananas, strawberries, and blueberries showed neither significant nor hazardous effects.

In summary, there is a possibility that fruit species have a differential effect on the risk of hypertension. However, while apples have the possibility to provide protective effects, there are currently too few studies on this subject to achieve consistent results.

\section{How about the Consumption of Fruit Juice?}

A prospective 20-year cohort of the Coronary Artery Risk Development in Young Adults Study examined the relationship between fruit juice intake (sweetened and unsweetened) and hypertension risk. ${ }^{39}$ Fruit juice intake was not significantly associated with incident hypertension (RR, 0.99; 95\% CI, 0.96-1.03). However, the fruit juice intake of participants was too low (approximately 1 cup per day) to estimate a practical dose-response relationship in the study. Furthermore, postmenopausal women enrolled in the Women's Health Initiative showed that 2 servings $(340 \mathrm{~mL})$ to 3 servings $(510 \mathrm{~mL}$ ) per day of $100 \%$ fruit juice neither increased nor decreased the risk of hypertension compared to $\leq 4$ servings $\left(680 \mathrm{~mL}\right.$ ) per week. ${ }^{40)}$ However, consuming $\geq 4$ servings $(680 \mathrm{~mL}$ ) per day of $100 \%$ fruit juice increased the risk of hypertension (HR, 1.29; 95\% CI, 1.06-1.56).

In summary, the consumption of fruit juice did not appear to increase the risk of hypertension at lower doses (approximately 1 cup per day). Moreover, a moderate intake of $100 \%$ fruit juice, up to 2-3 serving per day, was not significantly associated with the risk of hypertension. However, higher intake of $\geq 4$ servings ( $680 \mathrm{~mL}$ ) per day of $100 \%$ fruit juice did increase the risk of hypertension.

\section{IMPLICATIONS WHEN ANALYZING FRUIT INTAKE AND HEALTH-RELATED STUDIES}

Fruit intake itself is a marker of a healthy lifestyle, in that frequent fruit consumers are more likely to be physically active, drink less, be nonsmokers, consume multivitamin supplements, and have higher healthy eating index scores compared to infrequent fruit consumers. ${ }^{32,35,41)}$ Thus, the observed relationships between fruit intake and health outcome may be caused by measured and unmeasured residual confounding of healthy behavior.

There is also probable evidence that an increase in the consumption of fruits leads to weight reduction if they are replacing foods that are rich in fat or energy. ${ }^{42)}$ The protective effects of fruit consumption on blood glucose and blood pressure may be partly mediated through the anti-obesity effect of fruits. ${ }^{43)}$ Some studies have reported that the inverse relationships between fruit and blood glucose or blood pressure were attenuated or made non-significant when the models were adjusted for adiposity. ${ }^{37,38)}$ However, most studies have reported that adjustment of the adiposity index did not significantly change the association between fruit intake and blood glucose level ${ }^{19)}$ or blood pressure. ${ }^{35,36)}$ This suggests that fruits have other positive properties, such as anti-oxidative and anti-inflammatory effects, and ability to improve endothelial function and glucose metabolism, besides their anti-obesity effects.

Most studies we reviewed were either prospective cohort studies or meta-analyses of cohort studies. In the GRADE (Grading of Recommendations Assessment, Development and Evaluation) approach, observational studies received an initial grade of "low" because the RCT provide more robust evidence than observational studies. However, long-term randomized trials of health behavior are difficult to implement on a practical basis. In addition, as the interventions of health behavior were often designed multi-factorially, it was difficult to estimate the role of fruit intake alone on parameters of chronic diseases from multiple interventions. ${ }^{42)}$ Therefore, prospective observational studies may represent a more appropriate approach to investigate the role of fruit intake on blood pressure and blood glucose.

In terms of the limitations of this research, the included RCTs were small, and some meta-analyses showed substantial heterogeneity. Furthermore, for some questions, there have been an insufficient number of studies to obtain consistent results. Therefore, questions with inconsistent answers merit further investigation.

\section{CONCLUSION}

The consumption of $200 \mathrm{~g}$ of fruits per day appears to prevent T2D. These protective effects may differ according to fruit species, while fruit juices, particularly those that are sweetened with sugar, may increase the risk of T2D. Although fruits with lower glycemic load might be helpful for glycemic control in patients with T2D, the glycemic index or glycemic load of individual fruits did not seem to affect the incidence of diabetes. Furthermore, the consumption of up to $133 \mathrm{~g}$ per day of fresh fruit was shown to decrease the risk of complications and mortality in patients with T2D.

Fruit intake of up to $530-600 \mathrm{~g} / \mathrm{d}$ is protective against incident hypertension, which is higher than that required for a protective effect against T2D. The type of fruit may have a differential effect on the risk of hypertension, although further studies are required to confirm this hypothesis. Fruit juice did not seem to increase the risk of hypertension with the consumption of $<1$ cup per day of total fruit juice (sweetened and unsweetened) and 2-3 servings per day (340-510 mL per day) of $100 \%$ fruit juice. However, $>4$ servings $(680 \mathrm{~mL}$ ) per day, even of $100 \%$ fruit juice, increased the risk of hypertension.

\section{CONFLICT OF INTEREST}

No potential conflict of interest relevant to this article was reported.

\section{ORCID}

Hyun Ah Park: https://orcid.org/0000-0003-2343-8964 


\section{REFERENCES}

1. Liu RH. Health-promoting components of fruits and vegetables in the diet. Adv Nutr 2013;4:384S-92S.

2. Slavin JL, Lloyd B. Health benefits of fruits and vegetables. Adv Nutr 2012;3:506-16.

3. Macready AL, George TW, Chong MF, Alimbetov DS, Jin Y, Vidal A, et al. Flavonoid-rich fruit and vegetables improve microvascular reactivity and inflammatory status in men at risk of cardiovascular disease-FLAVURS: a randomized controlled trial. Am J Clin Nutr 2014;99:47989.

4. Zhao CN, Meng X, Li Y, Li S, Liu Q, Tang GY, et al. Fruits for prevention and treatment of cardiovascular diseases. Nutrients 2017;9:598.

5. Ministry of Food and Drug Safety. Korea nutrient database for standard reference. Cheongju: Ministry of Food and Drug Safety; 2020.

6. Klein AV, Kiat $\mathrm{H}$. The mechanisms underlying fructose-induced hypertension: a review. J Hypertens 2015;33:912-20.

7. Johnson RJ, Nakagawa T, Sanchez-Lozada LG, Shafiu M, Sundaram S, Le M, et al. Sugar, uric acid, and the etiology of diabetes and obesity. Diabetes 2013;62:3307-15.

8. Ministry of Health and Welfare. Korea health statistics 2018: Korea National Health and Nutrition Examination Survey (KNHANES VII-3). Sejong: Ministry of Health and Welfare; 2019.

9. Yeon S, Kweon S, Oh K. The daily dietary sugar intake in Korea, 2018. Public Health Wkly Rep 2020;13:359-63.

10. Korea Nutrition Society. Dietary reference intakes for Koreans 2015. Seoul: Korea Nutrition Society; 2015.

11. U.S. Department of Agriculture. Choose my plate [Internet]. Washington (DC): U.S. Department of Agriculture [cited 2020 Sep 5]. Available from: https://www.choosemyplate.gov/.

12. World Health Organization. Diet, nutrition and the prevention of chronic diseases: report of the joint WHO/FAO expert consultation. Geneva: World Health Organization; 2002.

13. Korean Diabetes Association. Treatment guideline for diabetes 2019. 6th ed. Seoul: Korean Diabetes Association; 2019.

14. American Diabetes Association. 5. Facilitating behavior change and well-being to improve health outcomes: standards of medical care in diabetes-2020. Diabetes Care 2020;43:S48-65.

15. Lee HY, Shin J, Kim GH, Park S, Ihm SH, Kim HC, et al. 2018 Korean Society of Hypertension guidelines for the management of hypertension: part II-diagnosis and treatment of hypertension. Clin Hypertens 2019;25:20.

16. Whelton PK, Carey RM, Aronow WS, Casey DE Jr, Collins KJ, Dennison Himmelfarb C, et al. 2017 ACC/AHA/AAPA/ABC/ACPM/AGS/APhA/ ASH/ASPC/NMA/PCNA guideline for the prevention, detection, evaluation, and management of high blood pressure in adults: a report of the American College of Cardiology/American Heart Association Task Force on Clinical Practice Guidelines. Circulation 2018;138:e484-594.

17. Li M, Fan Y, Zhang X, Hou W, Tang Z. Fruit and vegetable intake and risk of type 2 diabetes mellitus: meta-analysis of prospective cohort studies. BMJ Open 2014;4:e005497.

18. Schwingshackl L, Hoffmann G, Lampousi AM, Knuppel S, Iqbal K, Schwedhelm C, et al. Food groups and risk of type 2 diabetes mellitus: a systematic review and meta-analysis of prospective studies. Eur J Ep- idemiol 2017;32:363-75.

19. Li S, Miao S, Huang Y, Liu Z, Tian H, Yin X, et al. Fruit intake decreases risk of incident type 2 diabetes: an updated meta-analysis. Endocrine 2015;48:454-60.

20. Wu Y, Zhang D, Jiang X, Jiang W. Fruit and vegetable consumption and risk of type 2 diabetes mellitus: a dose-response meta-analysis of prospective cohort studies. Nutr Metab Cardiovasc Dis 2015;25:140-7.

21. Muraki I, Imamura F, Manson JE, Hu FB, Willett WC, van Dam RM, et al. Fruit consumption and risk of type 2 diabetes: results from three prospective longitudinal cohort studies. BMJ 2013;347:f5001.

22. Alperet DJ, Butler LM, Koh WP, Yuan JM, van Dam RM. Influence of temperate, subtropical, and tropical fruit consumption on risk of type 2 diabetes in an Asian population. Am J Clin Nutr 2017;105:736-45.

23. Imamura F, O'Connor L, Ye Z, Mursu J, Hayashino Y, Bhupathiraju SN, et al. Consumption of sugar sweetened beverages, artificially sweetened beverages, and fruit juice and incidence of type 2 diabetes: systematic review, meta-analysis, and estimation of population attributable fraction. BMJ 2015;351:h3576.

24. Xi B, Li S, Liu Z, Tian H, Yin X, Huai P, et al. Intake of fruit juice and incidence of type 2 diabetes: a systematic review and meta-analysis. PLoS One 2014;9:e93471.

25. Livesey G, Taylor R, Livesey H, Liu S. Is there a dose-response relation of dietary glycemic load to risk of type 2 diabetes?: meta-analysis of prospective cohort studies. Am J Clin Nutr 2013;97:584-96.

26. Christensen AS, Viggers L, Hasselstrom K, Gregersen S. Effect of fruit restriction on glycemic control in patients with type 2 diabetes: a randomized trial. Nutr J 2013;12:29.

27. Jenkins DJ, Srichaikul K, Kendall CW, Sievenpiper JL, Abdulnour S, Mirrahimi A, et al. The relation of low glycaemic index fruit consumption to glycaemic control and risk factors for coronary heart disease in type 2 diabetes. Diabetologia 2011;54:271-9.

28. Vaisman N, Niv E, Izkhakov Y. Catalytic amounts of fructose may improve glucose tolerance in subjects with uncontrolled non-insulin-dependent diabetes. Clin Nutr 2006;25:617-21.

29. Petersen KF, Laurent D, Yu C, Cline GW, Shulman GI. Stimulating effects of low-dose fructose on insulin-stimulated hepatic glycogen synthesis in humans. Diabetes 2001;50:1263-8.

30. Tanaka S, Yoshimura Y, Kawasaki R, Kamada C, Tanaka S, Horikawa C, et al. Fruit intake and incident diabetic retinopathy with type 2 diabetes. Epidemiology 2013;24:204-11.

31. Du H, Li L, Bennett D, Guo Y, Turnbull I, Yang L, et al. Fresh fruit consumption in relation to incident diabetes and diabetic vascular complications: a 7-y prospective study of 0.5 million Chinese adults. PLoS Med 2017;14:e1002279.

32. Wu L, Sun D, He Y. Fruit and vegetables consumption and incident hypertension: dose-response meta-analysis of prospective cohort studies. J Hum Hypertens 2016;30:573-80.

33. Schwingshackl L, Schwedhelm C, Hoffmann G, Knuppel S, Iqbal K, Andriolo V, et al. Food groups and risk of hypertension: a systematic review and dose-response meta-analysis of prospective studies. Adv Nutr 2017;8:793-803.

34. Liu Q, Ayoub-Charette S, Khan TA, Au-Yeung F, Blanco Mejia S, de Souza RJ, et al. Important food sources of fructose-containing sugars and incident hypertension: a systematic review and dose-response meta-analysis of prospective cohort studies. J Am Heart Assoc 
2019;8:e010977.

35. Kim J, Kim J. Association between fruit and vegetable consumption and risk of hypertension in middle-aged and older Korean adults. J Acad Nutr Diet 2018;118:1438-49.

36. Borgi L, Muraki I, Satija A, Willett WC, Rimm EB, Forman JP. Fruit and vegetable consumption and the incidence of hypertension in three prospective cohort studies. Hypertension 2016;67:288-93.

37. Liu MW, Yu HJ, Yuan S, Song Y, Tang BW, Cao ZK, et al. Association between fruit and vegetable intake and the risk of hypertension among Chinese adults: a longitudinal study. Eur J Nutr 2018;57:263947.

38. Wang L, Manson JE, Gaziano JM, Buring JE, Sesso HD. Fruit and vegetable intake and the risk of hypertension in middle-aged and older women. Am J Hypertens 2012;25:180-9.

39. Duffey KJ, Gordon-Larsen P, Steffen LM, Jacobs DR Jr, Popkin BM.
Drinking caloric beverages increases the risk of adverse cardiometabolic outcomes in the Coronary Artery Risk Development in Young Adults (CARDIA) Study. Am J Clin Nutr 2010;92:954-9.

40. Auerbach BJ, Littman AJ, Tinker L, Larson J, Krieger J, Young B, et al. Associations of $100 \%$ fruit juice versus whole fruit with hypertension and diabetes risk in postmenopausal women: results from the Women's Health Initiative. Prev Med 2017;105:212-8.

41. Oh JD, Lee SY, Lee JG, Kim YJ, Kim YJ, Cho BM. Health behavior and metabolic syndrome. Korean J Fam Med 2009;30:120-8.

42. Boeing H, Bechthold A, Bub A, Ellinger S, Haller D, Kroke A, et al. Critical review: vegetables and fruit in the prevention of chronic diseases. Eur J Nutr 2012;51:637-63.

43. Oh EJ, Joh HK, Lee R, Do HJ, Oh SW, Lym YL, et al. Relations between the dietary habits and components of the metabolic syndrome in premenopausal women. Korean J Fam Med 2008;29:746-61. 